\title{
Women's stress in compulsory army service in Israel: A gendered perspective
}

\author{
Ephrat Huss* and Julie Cwikel \\ The Center for Women's Health Studies and Promotion, The Spitzer Department of Social Work, Ben Gurion \\ University of the Negev, Beer Sheva, Israel
}

Received 30 May 2013

Accepted 13 May 2014

\begin{abstract}
.
BACKGROUND: A growing number of women are serving in the military in a variety of roles, yet information on their experience of stressors not associated with either combat or sexual harassment is not commonly reported.

OBJECTIVE: To present phenomenological data on stressors experienced in military service, together with the use of coping strategies as a way to focus on women's mental needs following deployment from service.

METHODS: Twenty women who had recently completed their compulsory army service in Israel drew a picture expressing stressors they experienced in the army. They analyzed their own pictures on three levels: the content, context, and the composition as expressing stress and the resources they used in coping with stress.

RESULTS: Six themes were raised: proximity to war situations, coping with accidents in training soldiers under their command, a conflict between political values and military orders, witnessing the injury of another female soldier, responsibility for accidental injury of a civilian, and distress over the army placement.

CONCLUSIONS: Coping resources were relational, primarily family and friend support, rather than from the army framework. This reliance on relational sources of support was both a resource and a source of vulnerability and is viewed as distinct from men's style of coping.
\end{abstract}

Keywords: Arts based research, self-in-relation model, Israel Defense Forces, PTSD symptoms

\section{Introduction}

Today, with prolonged wars occurring all over the globe, more and more women have experienced the stress of war, as soldiers, victims, family members or civilian populations. Women are generally more involved in army service and war than was common merely two decades ago. Israeli women, like their American counterparts, are serving in the armed forces in ever greater diversity of combat roles and involvement in areas of active military engagement $[21,22,36$, $74,75]$.

*Corresponding author: Ephrat Huss, The Center for Women's Health Studies and Promotion and The Spitzer Department of Social Work, Ben Gurion University of the Negev, Beer Sheva 84105, Israel. Tel.: +972 8 6428136; Fax: 9728 647877; E-mail: ehuss@ bgu.ac.il
Estimates show that the proportion of women serving in armed forces among NATO countries is below $10 \%$ in all European countries, $11.4 \%$ in Canada, and $14 \%$ in the United States [42]. In Israel, women constitute $34 \%$ of regular army personnel [5]. In light of these facts, it is imperative to develop genderappropriate ways of incorporating stressful war experiences without allowing traumatic memories to disrupt the adult capacities for education and job training, employment, establishing stable intimate relations, and parenting $[40,44]$. This will help the transition into civilian life and provide rehabilitative mental health services for those who need them.

Although women have long served in the Israeli Defense Forces (IDF) as part of their compulsory service from the age eighteen to twenty, there is a paucity of empirical research on the impact of their combat and 
service-related experiences on their functioning as they return to society as students, professionals, mothers, and in other significant relationships. This information could help provide insight into the types of stress that women experience in military service within specific cultural and gendered constructs, as well as the ways that they cope with this stress. Gender-specific findings could provide a basis for developing appropriate and supportive services for post-military rehabilitation specifically designed for women. A recent semiprospective study identified risk factors for the development of post-traumatic stress disorder (PTSD) during Israeli army service, but included only men. The authors commented: "Since some of the data were systematically missing for female subjects, we confined the sample to men only" [76, p. 1630]. Overall, little empirical research has been conducted on the selfreported stresses from military service-related trauma among Israeli women $[17,65]$. This may partly be due to the recent entry of women into combat roles, and partly due to the obvious concern that men in direct combat take precedence over women.

The assumptions of neurological and feminist literature are that women experience and cope with stress in different ways than men, especially when working in environments that have a male-oriented culture [12, 15]. These ways of coping may be hidden within a predominantly male and "macho" culture, such as that of the army. The aim of this paper is to undertake a preliminary exploration of how women experience and cope with stressful events in the IDF, with a methodology that specifies the type of stressor, their specific stress reactions and the methods they used in order to cope with the stressors.

\section{Survey of the literature}

Israel is the only country that has obligatory army service for both men and women (thirty-six months for men and twenty months for women), with extended service for officers $[65,76]$. Israel, in general, is considered a "stress laboratory", for its history of wars and terrorist events and for the concentration of conflicted groups of immigrants alongside myriad ethnic and religious groups. Thus, there is ongoing research into the personal and societal burdens associated with war and terrorist-related traumatic events. According to Amir and Sol's 1999 study on undergraduates, university students are twice as likely to have been officers $(20 \%)$ as the rate in the general community (10\%) and more likely to have combat exposure [2]. Once they have finished their obligatory military service, men and unmarried women continue to serve in the reserves up until the age of forty-five (for men) and thirty (for unmarried women) and thus may be repeatedly exposed to army stressors during their young adult lives. Israeli women participated in combat during the War of Independence, but subsequently were exempted from combat roles by the Law for Army Service of 1952 and served mostly in educational or administrative roles [49]. In 2000, the law was revised, opening up $90 \%$ of the IDF positions to women. Currently, $54 \%$ of able-bodied women serve in the IDF, with $34 \%$ getting a release on religious grounds. Women who are married and have children are exempted from compulsory service. Approximately $4 \%$ of women serve in combat roles with some units having much higher rates (e.g., light infantry $65 \%$ women; search and rescue $12 \%)$ [35,58].

There is no question that military service is high on the list of Potentially Traumatic Experiences (PTE) and qualifies as a Criterion A event for the diagnosis of Post-Traumatic Stress Disorder (PTSD) according to the DSM-IV-R [5,37]. PTEs occur more frequently and in many permutations during combat army service $[47$, $65,67,76]$. Acute stress reactions (ASR) in a war situation are termed "Combat Stress Reactions" (CSR) and are marked by an inability to function, either temporarily or chronically. Those with CSR or ASR reactions are much more likely to develop PTSD at a later time $[45,65]$.

Women are more likely to be exposed to posttraumatic stress associated with sexual violence or harassment while in the military, while men are more often exposed to post traumatic stress associated with combat situations $[13,41,70]$. This finding was replicated in a study of Israeli university students where $67 \%$ were exposed to at least one war stressor [2]; $56 \%$ of men and $6 \%$ of women had some army-related stress. However, that study was conducted more than ten years ago and since this time, as stated above, many more IDF roles were opened up to women recruits, including participating in combat units. Furthermore, specific questions addressing women's experiences, such as sexual harassment or the stress of commanding men during their service, were not included in this earlier study. An area that has been studied is the effect on wives when their husband has developed PTSD as a result of army service, when husbands were prisoners of war or career officers $[3,8,19,66]$ These studies confirmed interpersonal and parenting difficulties found in U.S. studies [25,33]. 
As shown above, quantitative data on women's army stressors are lacking; however, a 2007 documentary film by Tamar Yarom, "To See If I'm Smiling” ("No Place for a Lady" in its English version) documented the combat exposures of six women (selected out of the hundreds that Yarom interviewed) who served in the Israeli-administered territories during the Second Intifada (2000-2005). Five out of the six had not been in combat roles, but served in areas "under fire.” Personal and moral crises arose from friction with civilians, sexual harassment, and the handling of prisoners and corpses. These experiences were reviewed retrospectively with pain and doubt. There was also an unwillingness to disclose experiences to family and friends due to the "hero" culture in Israeli society concerning military service. Post-traumatic symptoms, such as a hypersensitivity to loud noises, crying and distress among their children were also salient [38]. These qualitative findings are congruent with how PTSD is expressed in the workplace. A recent review issue on this topic found numerous examples of how internal (person-specific) and external (work environment) factors affected the expression of PTSD symptoms following stressful events at work [52]. Female mental health professionals who worked in the IDF with both men and women have pointed out that, among soldiers who have had childhood traumatic experiences, the army can aggravate or reactivate traumatic memories because it overwhelms members with constant demands and scrutiny [32]. Preventive factors to mitigate PTSD risk are built into IDF practice for male combat soldiers today including immediate treatment and rallying of social support from the commander and unit soldiers. However, women are at particular mental health risk as they are not usually in combat roles and therefore these same resources are not available for them [32]. In general, women receive less training and are individually allocated to army bases without their peers who trained with them. Women in combat roles often adopt masculine mannerisms and speech to fit in [59]. Like male recruits, women are socialized to be "one of the guys," to not show distress or react overemotionally (exemplified by the movie "G.I. Jane"), and to not seek help to deal with PTEs. In addition, women are often exposed to both military PTEs and sexual harassment at the same time. In this context, they rarely complain about sexual harassment, which has been found to be widespread [48,59]. Sered commented that sexual harassment is so common in the army that women are expected to keep quiet and learn to cope [60].
Another consideration is that women and men experience high levels of stress differently. Findings from PTSD epidemiological research show that women are approximately twice as likely to develop PTSD as men, although the reasons are not clear. A recent review suggested a number of plausible factors including greater exposure to interpersonal, sexual violence, the younger age at trauma exposure, higher rates of peri-traumatic dissociative responses, insufficient access to social support and the interaction between stress responses and female hormonal exposure in adulthood [51]. All of these factors are relevant to the experiences of women in the army, yet it is difficult to find research that explores the effect of common stressful events for men and women. One study examined the PTSD risk of men and women exposed to the same non-sexual stressor (serious motor vehicle accidents). The results showed that women were much more likely to demonstrate avoidance, numbing, arousal, and difficulties in sleeping and concentrating and that these peri-traumatic reactions were associated with higher rates of PTSD [23]. After exposure to terror attacks, Israeli women were found to be more likely to develop symptoms of PTSD than Israeli men and these finding were replicated in both Jewish and Arab Israeli populations $[1,10,11]$.

In general, women tend to use emotion-focused rather than problem-focused coping [9,71]. Women also have a greater tendency to seek social support that helps in times of stress [69], which is consistent with the finding, reported earlier, that the lack of social support adversely affects women more than men. This is understood partially as a function of socialization that encourages women to express emotion and seek support from others $[53,55]$. It also is congruent with the relational model of women's psychological development, which posits that a "self in relation to others" is a core concept in women's psychological wellbeing [34, 50]. One study found that Israeli mothers living in the community frequently used emotional coping that connects them with friends and family, and their stress reactions focus on fear for others' safety, such as children and spouses [18]. There is little research which has focused on this relational stance, as it affects women's coping with stressors in the army.

This paper utilizes images as in arts-based research methods, not as a therapeutic medium, but as one suited to explaining army-based stressors for the following reasons. First, a significant finding in stress studies of war is that the most persistent symptoms of war-related stress and trauma were "recurrent im- 
ages and thoughts about the war" that were consistently most salient for both those with CSR and those without. Autobiographical memories that reflect experiences, both stressful and non-stressful, are stored as images through psycho-neurological mechanisms. Furthermore, a central component of most therapies for PTSD is the use of imagined exposures [46]. The individual is asked to recall a memory/image of the traumatic event while being guided to modify the image content or composition such as shape and color [72]. Eliciting memories through drawing involves different sensory input, addresses the symbolic manifestations, and creates a cognitive working zone for more positive re-interpretations of the traumatic events $[4,27,57]$.

Images contribute to human functioning, through helping to pursue goals and solve problems in light of past memories stored as images [16]. Images are thus at the intersection of both stress and coping methods. The projective nature of artwork provides a basis for identifying memories or images of stress and trauma that are safely removed to symbolism [24,56].

The visual images of war are a powerful reminder of combat exposures. Based on this finding, we utilized arts-based projective methods in this study to access these images, and to enable indirect narratives of stress to be expressed. In this fashion, we avoided the creation of psychological dissonance with the high value Israeli culture places on army experience and the special role of women in the army, which preclude telling stories of difficulties or stress during army service [59]. Images as indirect forms of narrative enable women to describe stressors and coping that may not be culturally acceptable within a male environment and so may not be described in direct verbal interviewing or questionnaires [29-31].

\section{Methods}

In light of the above, this paper uses a qualitative research design to assess context, stress reactions, and coping resilience. This research method has been previously used and published in earlier research on stress reported by civilian women during wartime [31]. The method uses self-reports of stressful situations experienced during army service that is turned into an image and explained three times by the research participants. The rationale for the qualitative method in this paper is that it is a preliminary explorative study that aims to point to and theorize about general themes that arise in the data. This exploratory stand is cited as appro- priate for preliminary studies and as a basis for further empirical studies [28].

The participants first explained the content and context of the stressor, then their specific stress reactions, and third their use of coping resources and strategies. The analysis was primarily based on the authors' phenomenological understanding of the content and accepted analyses of compositional elements that express both stress and coping [20,30,31,61]. Analysis was also based on the participants' phenomenological understanding of the content and on their descriptions of the compositional elements that express both stress and coping $[20,30,31,61]$. This method differs from projective arts tests that search for hidden content.

\subsection{Sample}

In the current study the researchers recruited twenty young women shortly after completing their army service who were undergraduate social work students. The women were all at a basic soldier rank, rather than officers. This study was viewed as a pilot for the conduct of a larger study of young adults; thus, we selected a population who would be cooperative and provide helpful feedback about the research process. The participants were recruited through a snowball method whereby respondents recommended additional suitable candidates for the research from their among their acquaintances [62]. The research assistants were trained in the use of the assessment tool, and implemented it with the students on an individual basis. After the procedure was explained, the students signed an informed consent form to participate in the study. The study was approved by the departmental ethics committee.

\subsection{Research tool}

1) Participants were asked to develop a single drawing of a stressful experience in the army (for example, when they witnessed someone who was wounded or they experienced a humiliating interaction). 2) They then were asked to explain their drawn experience and their stress reaction as expressed in the composition. Their verbal narrative was recorded and transcribed. 3) Finally, they were then asked to observe the image again, on the level of composition as well as content, and to define the stress reactions as they were manifested in the composition. For example, lots of black shading was interpreted by the respondent as depression, cut-off figures as elements they did not want to recall, and respondents contributed explanations on the 
symbolic meaning of various colors in their drawings. 4) Finally, they were asked to think about how they coped and to add or change shapes, colors, and contents within their image that represented these coping resources. For example, a respondent might have added an image of a friend to the picture or defining the contours of the self with a bolder contour to represent more protective boundaries [56,58].

\subsection{Analysis}

The study consisted of twenty case studies of the respondents' artwork and the overall narrative of the women interviewed. The data were analyzed thematically based on the above three parameters: content and context of the army stressor, stress reactions, and coping resources and strategies [20,30,31,61].

\subsection{Reliability}

Inter-coder reliability was established by review of the data by both researchers and the coding checked until a consensus was reached. Each student read part of the data in addition to the researchers and so there was a double analysis that created inter-coder reliability [73].

\subsection{Ethical considerations}

All participants signed consent forms to take part in the research and participated on a voluntary basis. The research was not connected to a course that they were taking, and so there was no pressure to participate. The use of social work students as research participants meant that they were practiced in self-regulating their emotional reactions and the method was not threatening or and had a negligible potential for emotional flooding for them. They also gained an enrichment tool for their own work. However, it should be noted that social work students differ in many ways, particularly in their awareness of psychological processes, from a random sample of female soldiers.

\section{Results}

As explained above, each image is analyzed three times by its creator, according to the stressor, the stress reactions, and their coping resources and reactions. The stressors presented in the twenty pictures were analyzed and divided thematically into six cen- tral content-based themes as presented in the following analysis [28]. Each theme is presented below by one typical case that represents this category (pseudonyms are used to protect confidentiality). These six themes were the most salient and appeared the most frequently in the analyzed materials (at a minimum twice).

Summary of cases presented:

The six themes that represented the types of stressors that women experience in the army were:

- Reactions due to proximity to active combat;

- Witnessing accidental injury of soldiers associated with combat training;

- Injury of a female friend;

- Having to participate in politically-based forced transfer of civilians;

- Personal responsibility for an error which caused injury to a civilian; and

- Unhappiness with the army placement received.

In the materials below, we selected one respondent whose answers and picture best typified each theme. For each example, we analyzed the material in the following categories based on the respondents' descriptions: a) the army-specific stressor, b) the stress response as expressed in the artwork, c) coping strategies added to the drawing and d) the authors' discussion of the thematic content as they reflect the diagnostic categories of PTSD [6].

\section{Presentation of the data}

\subsection{Sara (Proximity to fighting)}

a) Army stressor: Sara served in Gaza as part of a medical team in which she was very close to areas of combat. Sara drew life before the army in abstract calm colors (blue, green, and yellow) and after the army in strong warm colors (reds and browns) painted on top of the calm colors. She explained: "Both colors are now my life; I chose to make my drawing abstract because I couldn't verbalize a specific person or object, but a collection of experiences. I didn't separate the two periods of my life, the calm green one and the army red one, because they are now intertwined. Before my army service I didn't mind sirens, and now I'm hysterical when I hear them. The experience of the war that I took part in while in my army service has become part of me."

b) Stress reaction as expressed in the composition: "I cannot understand the abstract shape that I drew, maybe because it is too painful to remem- 
ber direct experiences, maybe this is a form of dissociation from the strong experience. The red covering up the former calm picture gives an uncomfortable feeling. I think I only used a small part of the page in an effort to encapsulate and control the experience and not let it control me."

c) Coping strategies: "I decided to add a blue hand, my hand. Blue symbolizes strength for me. A hamsa (a five-fingered palm that is a common protective symbol in the Middle East) is a cultural symbol of protection for Jewish people. Blue also reflects my love of our country and the ring on the hand symbolizes my husband, who helps me to overcome difficulties. The green duck is the wish to return peace and calm to my life."

d) Discussion: Sara is suffering from symptoms of disassociation, i.e., inability to verbalize a single incident, yet very overwhelmed by her experience) and intrusion (hysteria on hearing a siren), similar to PTSD symptoms. Because she was close to, but not directly involved in fighting, she did not receive help with these symptoms, and did not even think that she needed them. This represents a blind spot in the treatment of women in the army. We see that her coping methods are symbolic (remembering the calm before the army in general terms) and relational, towards her faith, country, and husband.

\subsection{Lea (Accidental injury during training)}

a) Army stressor: Lea served as a combat instructor, teaching soldiers to use a special type of tank. She explained, "I drew two very horrible things that happened to me: a tank is about to capsize, and the microphone in the tank did not work, so I couldn't notify the soldiers from my position as instructor that they were in danger. We called our unit leader, and he managed to solve the problem but it was very scary. In the second event, I was called to an emergency in the evening. I saw a man's helmet had fallen out of the tank. The soldier had wounded his head, and there was blood everywhere. I helped him to return to the base for medical care. I was so worried about the soldiers, and I was worried that I had done something wrong. I drew the clouds to show how it was evening and it's hard to move a tank in the evening. The green represents the soldiers' uniforms; they look green from far away. The tank is smaller, maybe because it's less important than the people." b) Stress reaction as expressed in the composition: "I think I controlled my fear of the tanks by making the whole picture look small and organized and controllable. The tanks are like toys. Although the red color makes it look like blood, the heavy grey clouds express my tension and the awful sense of responsibility for what happened, although I understand I was not to blame. I am also not their officer; even so, I felt so responsible. I can't get over it, both cases have blurred into one picture because of this heavy sense of responsibility."

c) Coping strategies: "To show how I coped, I added blue around myself, because blue calms me down, and I needed to be calm, and also the lines go to my friend Ruth, who helped me to calm down."

d) Discussion: While Lea did act in accordance with her responsibilities and managed to solve both problems while providing help to the soldiers, her subjective experience was of overwhelming tension due to the heavy responsibility associated with life-threatening situations beyond her control. Nonetheless, she managed to use her own coping resources to reduce her level of tension and also accessed social support from a friend outside of the army. Lea uses her explanation to demonstrate the conflict between knowing she was not responsible at a cognitive level while at the same time feeling overwhelming emotions of concern and worry. This could be a problem for women who are given defined responsibility for others in the army, but who feel responsible beyond their official role. As stated in the Introduction, we see that both Sara and Lea turned to external sources for support, rather than to someone within the army. This could be because they are alone in the unit, or with very few other women, It could also be because the army culture does not provide support for women who are supposedly less stressed because they are not in formal combat roles.

\subsection{Noa (Injury of a soldier friend at a checkpoint)}

a) Army stressor: "My job was to be an observer at a Palestinian checkpoint. A female terrorist managed to get into the observation area and shot at my (female) colleague, who was injured. I was not in the room when she shot her, but I had to identify my friend when she was taken to hos- 
pital. I drew the place but not what happened. I wanted to try to remember the place before that happened, the good people and beautiful view of sand dunes."

b) Stress reaction as expressed in the composition: "I see I totally omitted the event, and I also created a harsh black line as separation between the army base and the view I distanced myself from. I can't face it."

c) Coping strategies: "My coping strategies are my wish to focus on the 'good people' and on the view and on the pink color of the other female soldier who gave me a lot of strength."

d) Discussion: Noa's experience of secondary violence was traumatic and could not be directly expressed in the drawing. She used avoidance and distancing herself from the event in order to reduce the painful memory. Balancing the traumatic memory are the visual attributes of the place itself, which Noa remembered as beautiful. In addition, relational methods of coping were also included, expanding from connections to other supportive soldiers and one specific woman soldier who helped her to cope with the event and to calm herself.

\subsection{Orna (Civilian injury)}

a) Army stressor: "I was in charge of a checkpoint, and a Palestinian woman wanted to pass through and was accidently injured by IDF fire. I drew the woman, the check point fence and the green lawn behind her."

a) Stress reaction as expressed in the composition: "The fence is a reality but also an effort to create distance from the event. My sense of responsibility is expressed in the helplessness of the woman in that she has no hands and legs. I think this also expresses my helplessness. The arrows are my wish that it was possible to reverse the injury, so that I won't have to carry the guilt of her injury."

c) Coping strategies: "I tried to make the fence less strong and black, and I also softened it by adding white in order to bring the experience closer. The red is also blood but also the flowers in the area that give me strength. I turned to my friend for support."

d) Discussion: Orna experienced unresolved guilt at a civilian getting hurt under her command. Although she was not responsible for the injury she still felt responsible for the event. This em- phasizes the female tendency to take responsibility for others' well-being beyond the formalized boundaries of the relationship. Beauty and nature were again ways to create calm within the context of the drawing Note the use of social support to cope with conflict.

\subsection{Sharon (Conflict between political beliefs and army orders)}

a) Army stressor: "I had to be involved in the disengagement from Gaza as an officer. Although I personally do not agree with the political decision to force these people to leave their homes, I had to act against what I believed in. This was very hard for me. I drew a broken house of people forced to leave their house. I drew me with a huge head, trying to be rational, to disconnect from my emotions, but it felt like my head would explode."

b) Stress reaction as expressed in the composition: "I drew my head like a big red balloon, full of thoughts and filled with the color orange, the symbolic color of the group. It's like a balloon because it can blow up rather than contain the emotions. Green is the army people, and orange is the settlers. I see there is nothing else on the page, because I was obsessed, and my body is so small compared to the head, I see that the house cannot contain the people; it is transparent."

c) Coping strategies: "I drew a small blue house, my own home and family that gave me strength, and also maybe, when I think about it, it's the hope of the people here to have a new home in the future, this is what helps and contains me in this difficult situation, the hope for a better future."

d) Discussion: This example presents a central issue for both men and women who face compulsory service in the army, specifically when dissonance between army orders and personal ethics or ideology arises. We see that Sharon tried to resolve the tension by controlling her emotions and remaining rational. The relative size of her head to her body suggests that she let her rational side control her behavior and her choices. She was able to cope by anchoring herself in thoughts of her own family and home life, with the additional hope that many of those who were relocated would eventually live in a better situation. She uses two coping methods, both allowing one part of her to take control in a conflict and relying on relational support with her positive, emotional connections to her family. 


\subsection{Shira (Being unhappy in her allocated army base)}

a) Army stressor: "My stressor was being in a base that I hated. It took many months to get a transfer to another base and I tried desperately to move, but it still took many months. I spent days and nights crying - I was so unhappy there."

b) Stress reaction as expressed in the composition: "My stress reactions are apparent in the constant crying; that is me on the bed, me crying. There is nothing else. Also, there is a disconnection between the objects in the composition, and the other people being without content or faces."

c) Coping strategies: "Strengths were my home, my sisters who really helped me, so I drew a red roof, and my friends I added green, to make life more colorful and not only to have the base in my life. They gave me help and listened 24/7 no matter how hysterical and clingy I was. I now understand how blessed I am to have a good family and friends."

d) Discussion: The shift to compulsory service and lack of choice as to placement is culturally very different from the large amount of freedom and power that teenagers have in high school in Israel, which is a Western, individualistic culture. This culture shock often leads to a feeling of helplessness. Compared to many boys, we see that Shira is not culturally conditioned to express high identification with the army as an institution, but is focused on her personal experience. Being somewhere she was not happy was an intense stressor for her. The stress reactions were also typically female, presented as depressed mood and crying. She used intense connections to her sisters and family as her coping strategy. This is an example of stress created by the rigid and demanding framework of the army as contrasted with actual or secondary injury and threat of injury as expressed in the first three examples. While the first four sketches are considered typical PTEs, the last two examples are specific to women serving in the army and would not typically be considered as PTEs that would develop into PTSD.

\section{Discussion}

As stated at the beginning of the previous section, the findings point to six central themes about stress re- actions due to: proximity to active combat, witnessing accidental injury of soldiers associated with combat training, injury of a female friend, having to participate in politically-based forced transfer of civilians, personal responsibility for an error which caused injury to a civilian, and unhappiness with the army framework and with the placement received.

The narratives indicate that these young women found themselves in surprisingly stressful and threatening situations although they were not in actual combat situations or were themselves injured. The women's contexts involve physical harm proximate to others (including soldiers in their units, friends serving alongside them and civilians injured). The need to put a distance or contain the intrusive nature of the event was expressed in sentences such as "I see I totally omitted the event - I couldn't draw it, I still hear the sirens, it all merges into one thing - because I remember it so vividly, it colors everything, a bright red instead of the calm green before, even today.” These situations aroused intense stress reactions, including dissociation, re-experiencing, and a sense of loss of overall safety and calm on an ongoing basis. These reactions are similar to the post-traumatic reactions described in the literature characterized by symptoms of reexperiencing the trauma, intrusion, avoidance, numbing, and hyper-arousal. These stressors are found to occur more frequently and in many permutations during combat army service $[65,67,76]$ but also have an adverse effect on women's health after deployment [43, $63,64,68]$. Notably here, the stress symptoms are experienced also by women in proximity to, rather than through participation in, direct combat. This is congruent with the literature claiming that women are more sensitive to threats to significant others in their environment, even if they are not directly injured [12,15]. For example, after the September 11 attacks, women were twice as likely as men to report PTSD symptoms. Part of the factors that explained this heightened vulnerability were being the primary caretaker of children, having worked at rescue centers, and expressing concern for the community at large [54]. These findings echo earlier research from follow-ups of populations exposed to the Chernobyl explosion, which showed that mothers of small children were a high risk group for psychological distress due to worry over the effects of the exposure on their children's development [14].

In this small qualitative study, women did not report sexual harassment, although this is reported to be a very potent stressor for women in the army $[13,41$, $63,68,70]$. This lack of reporting sexual harassment has 
been found in other studies of women in the army [48, 59]. It is possible that they did not experience sexual harassment, or perhaps in the context of an interview by a fellow university student, disclosing sexual harassment would have been too difficult for the respondents. Perhaps it is simply less prevalent in the culture of the Israeli army. Another possible explanation is that this is an unrepresentative sample of social work students who were not exposed to sexual harassment in their army service.

The above post-traumatic symptoms are in line with the findings from PTSD epidemiological research, which show that women are approximately twice as likely to develop PTSD as men $[39,40,70]$. While the research states that the reasons are unclear, the qualitative data provided here suggest a possible explanation for this phenomenon. We see that in many of the stressors reported, women strived to adopt "male" coping mechanisms, such as problem-solving and rationalization while at the same time blocking their emotional reactions to the stressors. Despite their efforts, the emotional strain is apparent in their drawings in the colors chosen, the avoidance of the stressor events, and the disproportionate size of traumatic objects in relation to other objects in the drawings.

Similar to what has been reported, this paper also demonstrates how women try to modulate their emotional reactions by using more analytic and rational coping strategies [71]. For example, Lea attempted to cope by trying to shift from "warm" emotional colors, to "cool" colors or to move the distress from the body to the head (Sharon). These "cooler" reactions may be what they are learning from the surrounding men and are trying to emulate and provide a way of controlling the hot and emotional reactions that make them feel out of control. As noted in the literature review, women in combat roles often adopt masculine mannerisms and speech patterns to fit in [59]. Like male recruits, women are socialized to be "one of the guys," not to show distress or react overemotionally, and not to seek formal help for dealing with PTEs. This lack of access to social support within the army unit has been reported as a specific factor that makes women more vulnerable to the development of post-traumatic symptoms during their army service [67].

This effort to cope like men may, in turn, cut women off from more relational strategies of coping with stress, and leave them without access to resources from within the army. We saw that all of the women identified friends and families outside of the army that they turned to in order to shore up their coping skills and to whom they were able to safely vent their conflicted feelings about events. Emotional reactions were channeled into safer relational coping that was more accessible to them during their army service either with women friends or co-workers inside or family and friends outside of the army. For example, one study documented how women medical professionals collaborated in treating a complicated case of an injured soldier, which generated satisfaction among those involved in the case due to its successful resolution [26].

We see that the socialization to be "heroes like men" goes against the central emotive and support-seeking coping strategies typically adopted by women in stressful situations [31,53]. A major part of the stress was due to a relational and emotional connection and sense of responsibility towards others that exceeded their role definitions. We saw that the women did not report direct fear of death or injury, as men may feel in combat. Rather, they felt responsible for the male soldiers that they were training who were under their command or the civilians who were passing through their checkpoints. In light of this, it is important to take into account that research has shown that women have culturally constructed greater tendency to empathize and to take responsibility for others [7,9]. The implications are that being proximate to others who get hurt as paramedics, instructors, or support fighters can lead to experiencing more intense internalized worry and concern, thus potentially increasing the risk for traumatic stress responses as a result of army service. Having the additional responsibility of being an officer can also increase the exposure to combat or injury events that in turn become PTEs for women in the army.

At the same time, as stated above, finding social support through interpersonal connections was also the central coping strategy. In other words, the same emotional-relational network of relationships that created stress when others were threatened or injured was also the modulator of stress. This creates a paradox because if women do manage to disconnect from their relational forms of experiencing the stressors in the army (in other words become "cooler" or more rational like men) then they may also be cutting themselves off from their central source of strength or coping which is to connect to others for support. It may not be effective or helpful for them to intensify rationality, concrete problem solving, or control of boundaries of responsibility as do men. Another option may be to train women to be more versatile in their coping strategies; to engage both in focused problem-solving along with seeking support and counsel from others. 


\section{Conclusion}

Women's different style of coping has been explicated in feminist paradigms of women's mental health $[9,15,17]$. From a social perspective, it seems that when women soldiers operate within a male culture and adopt typical army values, they get caught between two opposing narratives or coping styles: the male and the female [73]. This delegitimizes their usual emotional, relational, and support-seeking behaviors that they have been socialized to use when dealing with stress by emphasizing stoicism, individualism, and rational problem solving, which are more masculine styles of coping. This explanation is strengthened by the example of the last category in which Shira was not happy in her army base. When the stress is not connected to a fighting context, but rather to general unhappiness with the army service, then the woman reverted to a typically female strategy of depressive mood and crying, allowing herself to express her vulnerability and distress. Another example of using social networks for social support under stress was reported by Orna who turned to her friend for support in dealing with her feelings when a civilian was injured.

The limitations of this study are that these findings are not compared to a similar phenomenological exploration of men's self-definitions of stress, that there are no comparisons with women who were in combat situations, and that the findings are based on a non-random sample. Additional research to validate the themes revealed in this study through the use of a quantitative survey with a closed questionnaire is a recommended direction for additional research, which the authors are now conducting. While this study has a small sample and the results are still preliminary, our findings clearly highlight the importance of using a gendered prism in understanding how female soldiers experience stress. Not all of women's stressors during their army service are associated with direct combat exposure, sexual harassment, and sexual assault experiences. As stated in the introduction, no comprehensive study has been conducted on the stresses of military service among Israeli women. The use of qualitative methods facilitated focus on the nuances of women's different coping styles. Our results highlight the paradox of relational perspectives as being both the source of stress and the same time a resource for coping. This understanding has implications regarding how women adapt to different army roles and types of mental health treatments of army-induced stress reactions that may be suitable for women serving in the army and after their release from the army.

While future studies are needed to validate and to elucidate these preliminary findings, some implications of this study are apparent. First, women experience acute PTEs yet these are often overlooked as forms of stress in the army, because they do not occur in the context of direct combat in areas of active military engagement. However, combat proximity and actual combat roles are increasing for women in the military for women both in Israel and in the United States, suggesting a trend of increasing exposure in women's army service $[58,67]$. Second, the army sources of support for women should provide help that is based not only on the ways that women experience stress, but also the ways that they cope with stress, both immediately and in the long-term as they transition to civilian roles and responsibilities. Third, the stress assessment method that we used in this study needs further refinement as a way to detect army associated PTEs. To this end, future studies are planned with a larger sample of women whose experiences will be compared with those of male soldiers.

As stated above, preventive factors to mitigate PTSD risk are built into IDF practice for male combat soldiers today, including immediate treatment and rallying of social support from the unit commander and other soldiers [32]. However, none of the women in this study mentioned army mental health, their army superiors, or officers as part of their support systems only family and friends. It seems that the Israeli army has not yet established the gender-specific frameworks through which women can access support when faced with overwhelming stressful army experiences without jeopardizing their working function in the IDF.

\section{References}

[1] Al-Krenawi A, Lev-Wiesel R, Sehwail MA. Psychological symptomatology among Palestinian male and female adolescents living under political violence 2004-2005. Community Ment Health J 2007; 43(1): 49-56.

[2] Amir M, Sol O. Psychological impact and prevalence of traumatic events in a student sample in Israel: The effect of multiple traumatic events and physical injury. J Trauma Stress 1999; 12(1): 139-154.

[3] Anson O, Rosenzweig A, Shwarzmann P. The health of women married to men in regular army service: Women who cannot afford to be ill. Women Health 1993; 20(1): 33-45.

[4] Appleton V. Avenues of hope: art therapy and the resolution of trauma. Art Therapy 2001; 18: 6-13.

[5] Association AP. Diagnostic and statistical manual for mental disorders. Washington, D.C.: American Psychiatric Press, 2000. 
[6] Association AP. Diagnostic and statistical manual of mental disorders. DSM-IV-TR. Washington, D.C.: American Psychiatric Association, 2000.

[7] Belle D. The stress of caring: Women as providers of social support. In: LGS Breznitz, editor. Handbook of stress: Theoretical and clinical aspects. New York: Free Press, 1982.

[8] Ben Arzi N, Solomon Z, Dekel R. Secondary traumatization among wives of PTSD and post-concussion casualties: distress, caregiver burden and psychological separation. Brain Inj 2000; 14(8): 725-736.

[9] Blalock JA, Joiner TE. Interaction of Cognitive Avoidance Coping and Stress in Predicting Depression/Anxiety. Cognitive Therapy and Research 2000; 24(1): 47-65.

[10] Bleich A, Gelkopf M, Melamed Y, Solomon Z. Emotional impact of exposure to terrorism among young-old and old-old Israeli citizens. Am J Geriatr Psychiatry 2005; 13(8): 705-712.

[11] Bleich A, Gelkopf M, Solomon Z. Exposure to terrorism, stress-related mental health symptoms, and coping behaviors among a nationally representative sample in Israel. Jama 2003; 290(5): 612-620.

[12] Bond EF. Women's physical and mental health sequellae of wartime service. Nurs Clin North Am 2004; 39(1): 53-68.

[13] Breslau N. Gender differences in trauma and posttraumatic stress disorder. J Gend Specif Med 2002; 5(1): 34-40.

[14] Bromet EJ, Havenaar JM, Guey LT. A 25 Year Retrospective Review of the Psychological Consequences of the Chernobyl Accident. Clinical Oncology 2011; 23(4): 297-305.

[15] Brown LS. Feminist paradigms of trauma treatment. Psychotherapy: Theory, Research, Practice, Training 2004; 41(4): 464-471.

[16] Conway MA, Pleydell-Pearce CW. The Construction of Autobiographical Memories in the Self-Memory System. Psychological Review 2000; 107(2): 261-288.

[17] Cwikel J, Ifrah A. The epidemiology of women's mental health in Israel: a life-course perspective. In: I Levav, editor. Psychiatric and behavioral disorders in Israel: From epidemiology to mental health action. Jerusalem, New York: Gefen, 2009, pp. 2-26.

[18] Cwikel J, Segal-Engelchin D, Mendlinger S. Mothers' coping styles during times of chronic security stress: effect on health status Health Care Women Int 2010; 31(2): 131-152.

[19] Dekel R, Solomon Z. Marital relations among former prisoners of war: contribution of posttraumatic stress disorder, aggression, and sexual satisfaction. J Fam Psychol 2006; 20(4): 709-712.

[20] Emmerson M, Smith P. Researching the visual: Images, objects, contexts and interactions in social research. Thousand Oaks, CA.: Sage, 2000.

[21] Fontana A, Rosenheck R. Treatment of female veterans with posttraumatic stress disorder: The role of comfort in a predominantly male environment. Psychiatr Q 2006; 77(1): 5567.

[22] Fontana A, Rosenheck R, Desai R. Female Veterans of Iraq and Afghanistan seeking care from VA specialized PTSD Programs: comparison with male veterans and female war zone veterans of previous eras. J Womens Health (Larchmt) 2010; 19(4): 751-757.

[23] Fullerton CS, Ursano RJ, Epstein RS, Crowley B, Vance K, Kao TC, Dougall A, Baum A. Gender differences in posttraumatic stress disorder after motor vehicle accidents. Am J Psychiatry $2001 ; 158(9)$ : 1486-1491.

[24] Furth G. The secret world of drawings: A Jungian approach to art therapy. Toronto: Inter City Books, 1998.

[25] Glenn DM, Beckham JC, Feldman ME, Kirby AC, Hertzberg
MA, Moore SD. Violence and hostility among families of Vietnam veterans with combat-related posttraumatic stress disorder. Violence Vict 2002; 17(4): 473-489.

[26] Gottshall K, Gray N, Drake AI. A unique collaboration of female medical providers within the United States Armed Forces: Rehabilitation of a marine with post-concussive vestibulopathy. Work: A Journal of Prevention, Assessment and Rehabilitation 2005; 24(4): 381-386.

[27] Hass-Cohen N, Carr R. Art therapy and clinical neuroscience. London: Jessica Kingsley, 2008.

[28] Hubberman M, Miles M. Reflections and advice. In: M Hubberman, M Miles, editors. The qualitative researchers companion. Thousand Oaks, CA.: Sage, 2002, pp. 393-399.

[29] Huss E. What we see and what we say: Using the Arts in Social Research and Practice. London: Routledge, 2012.

[30] Huss E, Cwikel J. Embodied drawings as expressions of distress among impoverished single Bedouin mothers. Archives of Women's Mental Health 2008; 11(2): 138-147.

[31] Huss E, Sarid O, Cwikel J. Using art as a self-regulating tool in a war situation: A model for social workers. Health and Social Work 2010; 35(3): 201-209.

[32] Ifergan A, Kamin N. Issues with women's army service, Proceedings of the The 3rd Annual Conference on Promoting the Mental Health of Women, 2008.

[33] Jordan BK, Marmar CR, Fairbank JA, Schlenger WE, Kulka RA, Hough RL, Weiss DS. Problems in families of male Vietnam veterans with posttraumatic stress disorder. J Consult Clin Psychol 1992; 60(6): 916-926.

[34] Jordan JV. Relational development: therapeutic implications of empathy and shame. In: JV Jordan, editor. Women's growth in diversity New York: Guilford Press, 1997.

[35] Kalfi-Amir G. Women's army service in the IDF (Hebrew). Tel Aviv: Office of the Advisor to the Chief of Staff for Women in Israel Defense Forces, Israel Defense Forces, 2008.

[36] Kang H, Dalager N, Mahan C, Ishii E. The role of sexual assault on the risk of PTSD among Gulf War veterans. Ann Epidemiol 2005; 15(3): 191-195.

[37] Karam EG, Andrews G, Bromet E, Petukhova M, Ruscio AM, Salamoun M, Sampson N, Stein DJ, Alonso J, Andrade LH, Angermeyer M, Demyttenaere K, de Girolamo G, de Graaf R, Florescu S, Gureje O, Kaminer D, Kotov R, Lee S, Lepine JP, Medina-Mora ME, Oakley Browne MA, Posada-Villa J, Sagar R, Shalev AY, Takeshima T, Tomov T, Kessler RC. The role of criterion A2 in the DSM-IV diagnosis of posttraumatic stress disorder. Biol Psychiatry 2010; 68(5): 465-473.

[38] Karpel D. My God, what did we do? A new film reveals the trauma of the female soldiers of the Intifada. Haaretz Magazine. Tel Aviv, 2007, pp. 14-17.

[39] Kessler RC. Gender and mood disorders. In: MB Goldman, MC Hatch, editors. Women \& Health. San Diego: Academic Press, 2000, pp. 997-1009.

[40] Kessler RC. Posttraumatic Stress Disorder: The Burden to the Individual and to Society. J Clin Psychiatry 2000 2000; 61(suppl 5): 4-12.

[41] Kessler RC, Sonnega A, Bromet E, Hughes M, Nelson CB. Posttraumatic stress disorder in the National Comorbidity Survey. Arch Gen Psychiatry 1995; 52: 1048-1060.

[42] Lamerson C. Committee on Women in NATO Forces, Year in Review 2001: North Atlantic Treaty Organization (NATO), Office on Gender Perspectives, 2001.

[43] Lang AJ, Laffaye C, Satz LE, McQuaid JR, Malcarne VL, Dresselhaus TR, Stein MB. Relationships among childhood maltreatment, PTSD, and health in female veterans in primary care. Child Abuse Negl 2006; 30(11): 1281-1292. 
[44] Levy BS, Sidel VW. Health effects of combat: A life-course perspective. Annu Rev Public Health 2009; 30: 123-136.

[45] Lilly MM, Pole N, Best SR, Metzler T, Marmar CR. Gender and PTSD: What can we learn from female police officers? Journal of Anxiety Disorders 2009; 23(6): 767-774.

[46] Lindauer RT, van Meijel EP, Jalink M, Olff M, Carlier IV, Gersons BP. Heart rate responsivity to script-driven imagery in posttraumatic stress disorder: Specificity of response and effects of psychotherapy. Psychosom Med 2006; 68(1): 33-40.

[47] Mattila AM, Crandall BD, Goldman SB. U.S. Army combat operational stress control throughout the deployment cycle: A case study. Work: A Journal of Prevention, Assessment and Rehabilitation 2011; 38(1): 13-18.

[48] Mazali R. And what about the girls? What a culture of war genders out of view. Nashim:A Journal of Jewish Women's Studies \& Gender Issues 2003; 6: 39-50.

[49] Midan A. Israeli women - barely hanging on to the status quo. Special article for Israel's 62nd Independence Day. Yediot Aharonot. Tel Aviv, 2010, pp. 4-10.

[50] Miller JB. Development of women's sense of self. No 12: Stone Center, Wellesley College, 1984.

[51] Olff M, Langeland W, Draijer N, Gersons BP. Gender differences in posttraumatic stress disorder. Psychol Bull 2007; 133(2): 183-204

[52] Precin P. Posttraumatic Stress Disorder and Work. Work: A Journal of Prevention, Assessment and Rehabilitation 2011; 38(1): 1-1.

[53] Ptacek JT, Smith RE, Zanas J. Gender, appraisal, and coping: A longitudinal analysis. Journal of Personality 1992; 60: 747770.

[54] Pulcino T, Galea S, Ahern J, Resnick H, Foley M, Vlahov D. Posttraumatic stress in women after the September 11 terrorist attacks in New York City. J Womens Health (Larchmt) 2003; 12(8): 809-820.

[55] Rosario M, Shinn M, March. H., Huckabee CB. Gender differences in coping and social supports: testing socialization and role constraint theories. Journal of Community Psychology 1988; 16: 555-569.

[56] Rubin JA. Approaches to art therapy: Theory and technique. New York: Brunner-Routledge, 2001

[57] Sarid O, Huss E. Trauma and acute stress disorder: A comparison between cognitive behavioral intervention and art therapy. The Arts in Psychotherapy 2009; 37: 8-12.

[58] Sarousi N, El-Peleg D. In the battlefield of the future we will be better than the men: Interview with Gila Kalfi-Amir, Commander of Women's Forces in the Israeli Defence Forces in honor of International Women's Day Bemahaneh (Hebrew) 2010: 31-35.

[59] Sasson-Levy O. Feminism and military gender practices: Israeli women soldiers in "masculine" roles. Sociological Inquiry $2003 ; 73(3)$ : 440-465.

[60] Sered S. What makes women sick? Maternity, modesty and militarism in Israeli society. Hanover and London: University Press of New England, Brandeis University Press, 2000.

[61] Silver D. Silver drawing test of cognition and emotion. Sarasota: Ablin Press, 2003.
[62] Silverman D. Doing qualitative research: A practical handbook. London: Sage Publications, 2000.

63] Smith BN, Shipherd JC, Schuster JL, Vogt DS, King LA, King DW. Posttraumatic stress symptomatology as a mediator of the association between military sexual trauma and postdeployment physical health in women. J Trauma Dissociation 2011; 12(3): 275-289.

[64] Smith TC, Ryan MA, Wingard DL, Slymen DJ, Sallis JF, Kritz-Silverstein D. New onset and persistent symptoms of post-traumatic stress disorder self reported after deployment and combat exposures: prospective population based US military cohort study. Bmj 2008; 336(7640): 366-371.

[65] Solomon Z, Ginzburg K. The epidemiology of combatinduced post-traumatic stress disorder (PTSD). In: I Levav, editor. Psychiatric and behavioral disorders in Israel: from Epidemiology to Mental Health Action. Jerusalem, New York: Gefen, 2009, pp. 212-232.

[66] Solomon Z, Waysman M, Levy G, Fried B, Mikulincer M, Benbenishty R, Florian V, Bleich A. From front line to home front: A study of secondary traumatization. Fam Process 1992; 31(3): 289-302.

[67] Street AE, Vogt D, Dutra L. A new generation of women veterans: stressors faced by women deployed to Iraq and Afghanistan. Clin Psychol Rev 2009; 29(8): 685-694.

[68] Suris A, Lind L, Kashner TM, Borman PD, Petty F. Sexual Assault in Women Veterans: An Examination of PTSD Risk, Health Care Utilization, and Cost of Care. Psychosom Med 2004; 66(5): 749-756.

[69] Taylor SE, Klein LC, Lewis B.P., Gruenewald TL, Gurung RAR, Updegraff JA. Biobehavioral responses to stress in females: Tend-and-befriend, not fight-or-flight. Psychol Rev 2000; 107: 411-429.

[70] Tolin DF, Foa EB. Sex differences in trauma and posttraumatic stress disorder: a quantitative review of 25 years of research. Psychol Bull 2006; 132(6): 959-992.

[71] Vingerhoets AJJM, Van Heck G. Gender, coping and psychosomatic symptoms. Psychol Med 1990; 20: 125-135.

[72] Vrielynck N, Philippot P. Regulating emotion during imaginal exposure to social anxiety: Impact of the specificity of information processing. Journal of Behavior Therapy and Experimental Psychiatry 2009; 40(2): 274-282.

[73] Wolf M. A thrice told tale. Feminism, postmodernism and ethnographic responsibility. Stanford, CA.: Stanford University Press, 1992.

[74] Zinzow HM, Grubaugh AL, Frueh BC, Magruder KM. Sexual assault, mental health, and service use among male and female veterans seen in Veterans Affairs primary care clinics: A multi-site study. Psychiatry Res 2008; 159(1-2): 226-236.

[75] Zinzow HM, Grubaugh AL, Monnier J, Suffoletta-Maierle S, Frueh BC. Trauma among female veterans: A critical review. Trauma Violence Abuse 2007; 8(4): 384-400.

[76] Zohar J, Fostick L, Cohen A, Bleich A, Dolfin D, Weissman Z, Doron M, Kaplan Z, Klein E, Shalev AY. Risk factors for the development of posttraumatic stress disorder following combat trauma: A semiprospective study. J Clin Psychiatry 2009; 70(12): 1629-1635. 